\title{
O QUE O CASO BRASILEIRO PODE OFERECER À COMPARAÇÃO GLOBALIZADA E GEOPOLÍTICA DOS CIRCUITOS EVANGÉLICOS DE SÉBASTIEN FATH: NOTA A PROPÓSITO DO SEU ARTIGO EM DEBATES DO NER
}

Marcelo Camurça

Resumo: Neste texto busco comentar o artigo de Sébastien Fath destacando aspectos de sua comparação entre o caso dos evangelicais no sul dos EUA de 1800-1850 com os pentecostais brasileiros de 1970-1980. Discuto o alcance das noções de história e de comparação tematizados no texto e concluo oferecendo mais dados sobre o caso brasileiro para municiar e robustecer mais o que chamei de experimento comparativo do artigo de Fath.

Palavras-chave: Evangélicos; Sul dos Estados Unidos; Pentecostais; Brasil.

\author{
WHAT THE BRAZILIAN CASE CAN OFFER TO THE GLOBALIZED \\ AND GEOPOLITICAL COMPARISON OF SÉBASTIEN FATH'S \\ EVANGELICAL CIRCUITS: NOTES ON HIS ARTICLE IN DEBATES DO NER
}

Abstract: This text seeks to comment on Sébastien Fath's article highlighting aspects of his comparison between the case of evangelicals in the southern United States from 1800 to 1850 with the Brazilian Pentecostals from 1970-1980. I discuss the scope of the notions of history and comparison as discussed in the text and

1 Como citar: CAMURÇA, Marcelo. O que o caso brasileiro pode oferecer à comparação globalizada e geopolítica dos circuitos evangélicos de Sébastien Fath: nota a propósito de seu artigo em Debates do NER. Debates do NER, Porto Alegre, v. 1, n. 37, p. 57-68, 2020.

2 Professor convidado no Programa de Pós-Graduação em Ciência da Religião da Universidade Federal de Juiz de Fora, Juiz de Fora, Brasil, e no Programa de Pós-Graduação em História Social da Universidade do Estado do Rio de Janeiro, Rio de Janeiro, Brasil. E-mail: mcamurca@terra.com.br. 
conclude by offering more data on the Brazilian case to equip and strengthen more what I called the comparative experiment of Fath's article.

Keywords: Evangelicals; Southern United States; Pentecostals; Brazil.

\section{INTRODUÇÃO}

Sébastien Fath, atual diretor do Laboratório Groupe Sociétés, Religions, Laïcités (GSRL) ligado à EPHE e ao CNRS é um pesquisador do fenômeno religioso evangélico articulado a imigração e a interculturalidade em contexto urbano. Constituem-se no foco de suas pesquisas os fenômenos da globalização e geopolítica envolvendo os grupos evangélicos. Exemplificando este seu labor acadêmico de alguns anos, pode-se citar dentre as dezenas de suas publicaçôes: Dieu bénisse l'Amérique: la religion de la Maison Blanche, (Seuil, 2000); Dieu change en ville: religions, espace, imigration, (L'Harmattan, 2010) e Gospel et Francophonie: une aliance sens frontiéres (Emprends Temps Présent, 2016).

Se seu campo de análise contempla a circularidade do movimento das igrejas evangélicas pela França, EUA, regiōes subsaarianas da África, neste texto intitulado "Das margens ao mainstream: desafios sociais da ascensão evangélica. Uma comparação transamericana”, ele, de forma inédita, estende seu olhar para o Brasil num experimento comparativo com uma região singular dos EUA, o Sul deste país.

O que ele propóe neste texto, no que diz respeito ao polo da comparação EUA, é deslocar o foco do lugar geral e usual do crescimento evangélico espraiado por todo o território norte-americano para a particularidade sulista dos "cinturóes bíblicos". O detalhamento desta realidade, onde o autor demonstra sólido conhecimento - destacando o declínio do anglicanismo, o ascenso contestador e popular de metodistas e batistas e após isto, a rotinização e capitulação destes ao establishment hierárquico-escravocrata 
- funciona como um contraponto para suas indagaçóes em relação ao outro polo da comparação, a realidade evangélica brasileira dos anos 1970-2010.

Ele, munido de sua exposição da realidade sulista dos EUA com a qual vai interpelar a realidade brasileira, terreno ainda pouco conhecido para ele, busca explorar as afinidades eletivas entre ambos os casos. Operação que se dá, em cima de uma provável dinâmica semelhante: declínio de uma religião hegemônica - o Anglicanismo no Sul dos EUA e a Igreja Católica no Brasil - avanço de religião minoritária para uma religião com extrema representatividade e apelo popular no caso do evangelicalismo norte-americano e do pentecostalismo brasileiro seguida de um processo de acomodação e adaptação em ambos ao sistema dominante. $\mathrm{O}$ experimento do autor visa responder à seguinte pergunta: o "tipo ideal evangélico conservador", que aparece como o perfil, comportamento e presença pública deste segmento tanto nos EUA quanto no Brasil, pelo qual a literatura acadêmica classifica o fenômeno, sairá "fortalecido" ou "nuançado"?

\section{HISTORICIDADE E COMPARATIVISMO}

Fath, dentro do seu experimento o coloca na perspectiva "dinâmica e comparada" alternativa a uma visão "estática" das duas realidades. Afinal, para o historiador que ele é, o devir e a transformação confluem nos seus estudos do fenômeno religioso para o mote "Deus muda" ("Dieu Change"). Este é o nome de um de seus livros relacionados acima; assim como do Programa/Seminário que dirigiu com Martine Cohen no GSRL por vários anos: "Dieu change à Paris" e também o nome de uma série de conferências que pronunciou em 2011 no Campus Condorcet.

Quando ele vai explorar o polo brasileiro da comparaçáo, como afirmei acima, assume o tom prudente de formular apenas indagaçóes, evitando afirmaçóes conclusivas. Afinal ele está comparando experiências sociais com cronologias bem diferentes, com cerca de 170 anos de décalage horaire, o que os historiadores poderiam classificar de "anacronismo". 
A legitimidade deste empreendimento, no entanto, já havia sido assegurada por Marcel Detienne com a fórmula provocadora de "comparar o incomparável" "não para impor leis gerais [...] [mas] para construir comparáveis, analisar micro sistemas de pensamento [...] estes encadeamentos procedendo de uma [...] escolha que temos a liberdade de colocar em relação a outras" para se alcançar "sociedades que mais frequentemente não se conhecem entre elas" (Detienne, 2009, p. 61-62). O procedimento analítico do estudioso helenista se assentando então, na tensão entre a homologia e a analogia.

\section{EXPLORANDO MAIS O CASO BRASILEIRO}

Penso que uma contribuição que este comentário, ainda que de forma exploratória, poderia oferecer ao experimento de Fath, seria de cobrir certas lacunas para o caso brasileiro, a partir de algumas chaves propostas por ele nas suas indagaçôes.

Portanto, como um feedback ao texto do nosso colega Fath no seu intento de aproximar seu olhar, de forma comparada para as duas Américas: sul e norte - perspectiva "transamericana" como ele se refere no título do seu texto - passo a me concentrar em algumas singularidades do caso brasileiro que exemplificam nossa também trajetória de "margem a mainstream".

Teria o movimento evangélico pentecostal brasileiro se constituído na sua gênese como utópico, transgressor e insubmisso do ponto de vista social como no caso dos metodistas/batistas do sul dos EUA, para depois cair na rotinizaçáo e conservadorismo?

A literatura acadêmica brasileira sobre esse tema tem se dividido entre trabalhos que dão ênfase a capacidade da proposta evangélica produzir estratégias de sobrevivência e padróes de identidade para as camadas empobrecidas da população e outras que sublinham o caráter conservador de sua mensagem com relaçáo à liberalização dos costumes, anti-intelectual em relação à ciência e às políticas públicas e confessional em relaçáo ao Estado Laico. 
No primeiro caso, pesquisas vêm revelando como a mensagem pentecostal é eficaz do ponto de vista simbólico no empoderamento feminino, na superação do alcoolismo, em conferir dignidade e autoconfiança diante da violência e da pobreza na vida nas favelas e bairros populares (Mariz, 1994a, 1994b; Machado, 1996, 2001; Mafra, 2009; Costa, 2019).

No segundo caso, o artigo referência de Antônio Flávio Pierucci (1989), que sublinhou a presença conservadora dos evangélicos na Constituinte de 1988, propiciou o surgimento de uma série de pesquisas que focam na atuação política e de ocupação do espaço público pelos evangélicos numa linha de expansão de sua visão confessional para os domínios seculares.

O que estes estudos destacam é uma ação consciente por parte das lideranças eclesiais evangélico-pentecostais de estender sua representatividade do campo religioso para uma preeminência no espaço público através da uma projeção da visão moral e dogmática cristã para as instituiçóes públicas (Mariano; Oro, 2010; Tadvald, 2015; Trevisan, 2013). Nesta ação eles se confrontam com projetos laicos e da sociedade civil de descriminalizaçáo do aborto, da união civil entre homossexuais, de descriminalização das drogas, da inclusáo dos direitos sexuais e reprodutivos no rol dos direitos humanos. E também se confrontam com os setores laicos, quando propóem o ensino religioso na escola pública, a presença de símbolos religiosos em locais públicos, etc. (Mariano, 2011).

Sintetizando as duas ênfases das pesquisas, pode-se dizer, que embora com apelo popular, como agente da resistência as adversidades entre os mais empobrecidos, desde sua gênese, o pentecostalismo traz no seu "DNA" a marca do conservadorismo. E a passagem de "margem a mainstream" aqui no Brasil foi principalmente uma questão de aumento e amplificação deste seu intrínseco conservadorismo religioso.

Prosseguindo, Sébastien Fath elencou alguns domínios ou temas para assentar suas indagaçóes sobre a situação brasileira em contraste com o caso do sul dos EUA: modernidade; cultura tradicional ou liberal e separação de poderes entre Igreja e Estado e o perfil de Estado Laico. Passo, então, a comentários sobre essas questóes. 


\section{MODERNIDADE}

O uso da chave da "modernidade", dentro do modelo weberiano que associa protestantismo a esta etapa civilizatória, serve como um referente para Fath especular sobre a adesão dos evangélicos brasileiros à cultura estabelecida ou às transformaçôes em curso na sociedade? Sobre isto, teria a dizer o seguinte: Sim, o movimento evangélico-pentecostal se inscreve no quadro da modernidade, mas de uma modernidade conservadora.

É modernidade, pelo foco na escolha do indivíduo - tema que desenvolverei em seguida no tópico da cultura - e também pelo seu modo de propagação: dentro do estilo moderno de atuação: meios de comunicação (imprensa, rádio, televisão), lobby no parlamento, manifestaçôes de rua, como as "Marchas para Jesus". Tudo isto para se confrontar com outra modernidade liberal e plural.

A partir de uma mentalidade conservadora e ascética, interpenetram-se nas esferas profanas dos mass media e do lazer e consumo, levando ao desenvolvimento de um mimetismo do religioso com estilos de vida moderna revestindo-os com a rubrica sagrada do gospel: "atletas de Cristo", o funk evangélico, inserçôes das bandas gospel de sucesso no YouTube, os "pancadôes de Jesus", grandes bailes com som techno que atraem a juventude nos subúrbios metropolitanos. O "turismo evangélico", o amplo mercado fonográfico de CDs e DVDs que popularizam as pop stars evangélicas Rose Nascimento, Lúcia Lombardi ou Ana Paula Valadão.

\section{CULTURA TRADICIONAL OU LIBERAL E QUESTÃO RACIAL}

Dentro da comparação dos evangélicos do Sul dos EUA com os do Brasil, Fath levanta a questão de os primeiros surgirem como "contracultura" e terminarem por aderir à cultura tradicional hierárquica-escravocrata da regiāo. A partir deste quadro estadunidense ele indaga se os evangélicos brasileiros possuem algum potencial cultural transformador ou terminam por se acomodar à cultura tradicional. 
Como resposta à questão de Fath, é importante dizer que a cultura evangélico-pentecostal no Brasil, embora mobilizadora das camadas populares em experiências extáticas/carismáticas, o que lhe causou problemas e até expulsóes das igrejas consolidadas - como o caso dos que vieram a formar a nascente Assembleia de Deus em relação à Igreja Batista -, nunca foi libertária em termos de justiça social e projeto de classe.

Por outro lado, na comparação em termos de questão racial, a indagação de Fath se situa na hipótese, dentro do exemplo do Sul dos EUA, de o movimento evangélico nas camadas populares gerar uma igreja étnica de negros ou igrejas multiétnicas e mestiças, como ele intui ser o caso brasileiro.

Pierucci, a partir de uma pesquisa do Datafolha de 1994, revela que no segmento negro se encontra a taxa mais alta de filiação ao credo evangélico e mais ainda: que há mais negros no segmento evangélico do que em qualquer outra religiáo (Pierucci, 2006, p. 27). Daí porque chamar o fenômeno de "black evangelicals" (Pierucci, 2006, p. 24). Mas ao contrário desta ser uma religiấo étnica, ele mostra que este tipo de religião é disruptivo em relação às tradicionais religióes étnicas, como as afro-brasileiras, funcionando como um religiâo de salvação individual de caráter universal. Ou seja, o que congrega estes indivíduos não é a tradição nem a etnia, mas a promessa de salvação (Pierucci, 2006, p. 30-32). E o fato, digo eu, de ser predominantemente uma religiâo difundida entre negros, não significa que a negritude seja o ponto de coesão, mas sim a escolha individual do "aceitar Jesus" e dos milagres que essa opção operará na vida do "eleito".

Aqui, poderíamos afirmar que - entre cultura e raça - o que prevalece é uma atitude cultural moderna da escolha individual. Porém, como disse antes, que se trata de uma opção por uma modernidade de tipo conservadora, pois sua pedra de toque em termos de projeto para o bem comum da sociedade se resume a moralidade calcada em valores religiosos. 


\section{SEPARAÇÃO ESTADO/IGREJA}

Neste desdobramento da questáo moderna e cultural, Fath apresenta a questão do secularismo e laicidade nas indagaçóes que faz ao caso brasileiro. No caso, pergunta sobre se os pentecostais da atualidade acompanharáo os protestantes históricos no seu libelo pela separaçáo da Igreja do Estado no período de "concordata implícita" entre o Estado brasileiro e a Igreja Católica que acompanhou quase toda a história republicana no Brasil.

$\mathrm{Na}$ verdade, o advento dos evangélico-pentecostais no cenário público no Brasil, não gerou um clamor pela separação Igreja/Estado em prol de uma "comunidade de eleitos" alternativa a "Igreja de Estado". Ao contrário, pouco a pouco passaram a querer os mesmos privilégios concedidos a Igreja Católica para eles. Um exemplo disto foi o questionamento pela Frente Parlamentar Evangélica do acordo em forma de Concordata que o governo Lula firmou em 2008 com o Vaticano, para em seguida entabularem uma negociação parlamentar que redundou na Lei Geral das Religiôes. Esta estendia as mesmas cláusulas da concordata com a Igreja Católica para os demais credos representativos - leia-se, os evangélicos. Isto, e não o impedimento de qualquer relação do Estado com as religióes, como queriam os minoritários deputados laicos do PSOL (Ranquetat Júnior, 2010, p. 179-181).

O sociólogo mexicano Roberto Blancarte (2011, p. 24) já chamava a atenção para uma compreensão vigente de laicidade na América Latina como sendo o de uma "pluriconfessionalidade", ou seja, uma outorga dos privilégios históricos conferidos à Igreja Católica a todas outras igrejas com capacidade de representação e mobilização política, ou seja, as igrejas evangélico-pentecostais.

Portanto, dentro da fórmula "O Brasil é um país laico, mas não ateu", os parlamentares evangélicos pentecostais trabalham para que seus valores religiosos venham influir nas decisões de Estado com relação à sociedade, devido ao que julgam ser o peso da sua presença religiosa na sociedade. 


\section{OUTRAS POSSIBILIDADES DE COMPARAÇÃO}

Uma outra possibilidade de comparação entre evangélicos pentecostais nos EUA e no Brasil que poderia ser sugerida à pesquisa de Fath - que em termos de marcos temporais colocaria as duas realidades em condiçôes homólogas - seria entre a intervenção política do movimento "Moral Majority” do pregador evangélico Jerry Falwell a partir dos anos de 1979 que aumentou a influência dos cristãos conservadores nos governos Reagan, Bush (pai e filho) e atualmente no de Trump com a crescente influência da Frente Parlamentar Evangélica no Congresso Nacional da Constituinte de 1988 aos anos 1990, 2000. Não foi por outro motivo, que o já citado artigo de Antônio Flávio Pierucci (1989) fazia a analogia de nossa "bancada evangélica” com a New Christian Right estadunidense na sua reivindicação de representar uma "maioria moral" (silenciosa) do povo norte-americano em termos de valores morais conservadores. E aqui podemos encontrar outra afinidade eletiva com a situação do Brasil, com a questão do "populismo" evocada por Fath, quando líderes carismáticos estadunidenses "falando em nome do povo e dos valores cristãos" buscam influenciar na legislação estatal querendo impor a "virtude pela lei".

No que diz respeito à trajetória de "margem a mainstream" neste escopo de comparação mais amplo poder-se-ia propor o seguinte: para o caso dos EUA, teríamos do século XIX até o período dos anos 1920 a 1940 a predominância do "liberalismo teológico" ou "modernismo teológico" para a partir dos anos 1970 verificarmos a irrupção da gradativa presença pública dos evangélicos conservadores até então minoritários ou reclusos nos seus nichos privados (Silva, Barbosa, 2019). E para o caso do Brasil, o chamado apoliticismo dos evangélicos pentecostais ao longo de sua presença histórico-social no país ofuscados pela hegemonia do Catolicismo, para sua marcante visibilidade na Constituinte de 1988 e a partir daí vertiginoso crescimento (Mariano, 2011).

Uma série de situações da realidade dos EUA dos anos 1970 a 1980 podem ser identificadas na ação religiosa-política dos nossos evangélicos/ 
pentecostais a partir de 1988. Além do que foi mencionado acima: ambos inicialmente distantes da política e do espaço público, mas a partir de determinado período inserindo-se nestes loci, temos também a organização de lobby para eleição de candidatos que defendem projetos religiosos conservadores para a conquista do poder; a luta contra a secularização e a dita "descristianização" do país; a organização a partir da liderança evangélica de uma frente conservadora atraindo católicos tradicionalistas e judeus ortodoxos (a Moral Majority); a utilização da noção de "liberdade religiosa" para defender seu direito de atacar projetos de lei contra a discriminaçáo do aborto e da orientação sexual; a crítica à "educação sexual" nas escolas públicas como promotora de "perversão" e "imoralidade"; a diminuição da importância das igrejas e "denominaçóes" clássicas em prol das grandes estruturas "para-eclesiásticas" ou "inter-denominacionais", como as nossas "bancadas evangélicas" e "Marcha para Jesus", etc.

Outra relação entre evangélicos nos EUA e Brasil é a que nos traz Cecília Mariz em texto que contempla a "teologia da guerra espiritual". Nele a autora sublinha que esta teologia conhecida como "Dominion Theology" foi criada nos EUA pelo pastor Peter Wagner e chegou ao Brasil através das missóes da rede "Guerra Espiritual Internacional", coordenada pelo referido pastor (Mariz, 1999, p. 34). Na conclusão de seu texto, Mariz, ao comparar nossos evangélicos pentecostais com os evangelicals norte-americanos, pioneiros da "guerra espiritual", diz que a ênfase dos segundos era contra "os costumes sexuais modernos e as teorias científicas" ao passo que no nosso caso a "guerra santa" se voltava contra as religióes afro-brasileiras, demonizadas por aqueles (Mariz, 1999, p. 48). Do final dos anos 1990, quando foi escrito o texto de Mariz, até nossos tempos presentes, pode-se constatar que os evangélicos brasileiros na sua expansão para o espaço público, estenderam sua "guerra" também aos costumes liberalizados de vida moderna, assim como aos domínios científicos e laicos. Os recentes episódios no país de grandes concentraçóes pentecostais se rebelando contra as determinaçóes de confinamento do Ministério da Saúde e da OMS, expondo-se à contaminação da 
COVID-19 e clamando pelo "milagre divino", tudo isto é ilustrativo destas práticas de confessionalização da sociedade e do Estado perpetradas por eles.

\section{REFERENCIAS}

BLANCARTE, Roberto. América Latina: entre pluri-confesionalidad y laicidad. Civitas: Revista de Ciências Sociais, Porto Alegre, v. 11, n. 2, p. 182-206, 2011.

COSTA, Waldney de Souza Rodrigues. Curtindo a presença de Deus: religião, lazer e consumo entre crentes e cançóes. 2019. Tese (Doutorado em Ciência da Religião) - Programa de Pós-Graduação em Ciência da Religião, Universidade Federal de Juiz de Fora, Juiz de Fora, 2019.

DETIENNE, Marcel. Comparar o incomparável. São Paulo: Ideias e Letras, 2010 .

MACHADO, Maria das Dores Campos. Carismáticos e pentecostais: adesão religiosa na esfera familiar. São Paulo: ANPOCS, 1996.

MACHADO, Maria das Dores Campos. Olhando as mulheres pentecostais através do espelho. In: VALLA, Victor Vincent (org.). Religião e cultura popular. Rio de Janeiro: DP\&A, 2001. p. 79-90.

MAFRA, Clara. Distância territorial, desgaste cultural e conversão pentecostal. In: MAFRA, Clara; ALMEIDA, Ronaldo de (org.). Religióes e cidades: Rio de Janeiro e São Paulo. São Paulo: Editora Terceiro Nome, 2009. p. 69-89.

MARIANO, Ricardo. Laicidade à brasileira: católicos, pentecostais e laicos em disputa na esfera pública. Civitas: Revista de Ciências Sociais, Porto Alegre, v. 11, n. 2, p. 238-258, 2011.

MARIANO, Ricardo; ORO, Ari Pedro. Eleições 2010: religião e política no Rio Grande do Sul e no Brasil. Debates do NER, Porto Alegre, v. 2, n. 18, p. 11-38, 2010. 
MARIZ, Cecília Loreto. Alcoolismo, gênero e pentecostalismo. Religiāo \& Sociedade, Rio de Janeiro, v. 16, n. 3, p. 80-93, 1994 a.

MARIZ, Cecília Loreto. A teologia da batalha espiritual: uma revisão da literatura. BIB, Rio de Janeiro, n. 47, p. 33-48, 1999.

MARIZ, Cecília Loreto. Libertação e ética: uma análise do discurso dos pentecostais que se recuperaram do alcoolismo. In: ANTONIAZZI, Alberto et al. Nem anjos nem demônios: interpretaçôes sociológicas do pentecostalismo. Petrópolis: Vozes, 1994b. p. 204-224.

PIERUCCI, Antonio Flávio. Ciências sociais e religião: a religião como ruptura. In: TEIXEIRA, Faustino; MENEZES, Renata (org.). As religiōes no Brasil: continuidades e rupturas. Petrópolis: Vozes, 2006. p. 17-34.

PIERUCCI, Antonio Flávio. Representantes de Deus em Brasília: a bancada evangélica na Constituinte. Ciências Sociais Hoje, São Paulo, n. 11, p. 104-132, 1989.

RANQUETAT JÚNIOR, César Alberto. O acordo entre o governo brasileiro e a Santa Sé e a Lei Geral das Religiôes: Estado, religião e política em debate. Debates do NER, Porto Alegre, ano 11, n. 18, p. 173-191, 2010.

SILVA, Ivan Dias da; BARBOSA, Wilmar do Valle. Religião e política nos Estados Unidos: Jerry Falwell e a presença do fundamentalismo evangélico no espaço público americano. Curitiba: Prismas: Appris, 2019.

TADVALD, Marcelo. A reinvenção do conservadorismo: os evangélicos e as eleiçôes federais de 2014. Debates do NER, Porto Alegre, ano 16, n. 27 , p. 259-288, 2015.

TREVISAN, Janine. A Frente Parlamentar Evangélica: força política no Estado laico brasileiro. Numen, Juiz de Fora, v. 16, p. 29-57, 2013.

Recebido em: 14/04/2020

Aprovado em: 14/04/2020 